\title{
Development and first application of an audit system for screening programs based on the PRECEDE-PROCEED model: an experience with breast cancer screening in the region of Lombardy (Italy)
}

\author{
Danilo Cereda ${ }^{1 *}$ (D) Antonio Federici ${ }^{2}$, Angela Guarino ${ }^{3}$, Grazia Serantoni ${ }^{4}$, Gruppo PRECEDE-PROCEED ${ }^{5}$,
} Liliana Coppola ${ }^{1}$, Patrizia Lemma ${ }^{6}$ and Paolo Giorgi Rossi

\begin{abstract}
Background: High participation and performance are necessary conditions for the effectiveness of breast cancer screening programs. Here we describe the process to define and test a planning software application and an audit cycle based on the PRECEDE-PROCEED model applied to improving breast cancer screening. We developed a planning software application following the phases of the PRECEDE-PROCEED model. The application was co-designed by local cancer screening program coordinators. An audit model was also developed. The revised application and the audit model were tested by all the coordinators of 15 breast cancer screening programs in the region of Lombardy in a 3-day workshop. The project plans produced using the application were compared with those produced in the previous year for clarity and completeness.

Results: The 9 phases of the PRECEDE-PROCEED model were adapted to screening as follows: 1) identification of program goals (i.e., participation, sensitivity, false positive); 2) epidemiological issues; 3) best practices analysis; 4) evidence-based actions to be implemented in the screening center and the relationships with partners and stakeholders; 5) priority setting and identification of solutions for each issue; 6) definition of indicators; 7) monitoring; 8) evaluation; 9) impact assessment. The application automatically generated reports for each phase. During the audit cycle, the regional health authority negotiated the targets to be reached with local authorities and collected the improvement plans generated by the application. The plans produced after the application was adopted were more standardized and had clearer indicators for monitoring and evaluation compared to those produced in the previous year.
\end{abstract}

Conclusions: The software application helps standardize criteria for planning interventions to improve screening programs and facilitates the implementation of the audit cycle.

Keywords: Breast cancer, Mass screening, Health intervention planning, PRECEDE-PROCEED model, audit

\footnotetext{
* Correspondence: danilo_cereda@regione.lombardia.it

${ }^{1}$ DG Welfare, Regione Lombardia, Milano, Italy

Full list of author information is available at the end of the article
}

(c) The Author(s). 2020 Open Access This article is licensed under a Creative Commons Attribution 4.0 International License, which permits use, sharing, adaptation, distribution and reproduction in any medium or format, as long as you give appropriate credit to the original author(s) and the source, provide a link to the Creative Commons licence, and indicate if changes were made. The images or other third party material in this article are included in the article's Creative Commons licence, unless indicated otherwise in a credit line to the material. If material is not included in the article's Creative Commons licence and your intended use is not permitted by statutory regulation or exceeds the permitted use, you will need to obtain permission directly from the copyright holder. To view a copy of this licence, visit http://creativecommons.org/licenses/by/4.0/. The Creative Commons Public Domain Dedication waiver (http://creativecommons.org/publicdomain/zero/1.0/) applies to the data made available in this article, unless otherwise stated in a credit line to the data. 


\section{Background}

In Italy breast cancer screening has been recommended since 1999. The Regions have received a mandate to implement programs to actively invite women aged 50-69 to perform a mammography every 2 years [1]. Nevertheless, the activation of screening programs has been slow; in 2015 , on average $18 \%$ of the target population was not regularly invited for a screening test, with strong differences between geographical areas (ranging from 3\% in the North to $40 \%$ in the South). Furthermore, participation has been low, ranging from 31 to $77 \%$ among the regions [2].

Many studies, both international [3, 4] and Italian [58], have shown that organized screening has a more appropriate diagnostic pathway and better performance than does spontaneous or opportunistic screening. Furthermore, at least in European countries, organized programs showed to obtain higher test uptake [4] thus a stronger impact on breast cancer mortality in the target population. Even if the best way to measure the effectiveness of the screening program in informing the target population should be monitoring informed choice of the women, it is difficult to measure it, thus the European Council Initiative on Breast Cancer supported the use of participation as a good proxy of informed choice $[9,10]$ for the age group where the guidelines made a strong recommendation in favor of screening [11].

Previous systematic reviews identified several determinants and interventions which proved to be effective in increasing the uptake of mammography, including mail reminders, telephone calls, GP signature on the invitation letter, pre-fixed appointment compared to open invitation to fix an appointment, and strategies to reduce logistical barriers [12, 13].

In 2014, order to promote effective interventions to increase participation in organized cancer screening programs and to improve their implementation and performance, the Italian Ministry of Health started a project ("Implementation of screening programs: analysis of barriers and facilitating factors, modifiable and not" [14]) coordinated by AGENAS (the National Agency for Regional Health Services) and in collaboration with a group of regions that agreed to participate with the aim of understanding and overcoming the barriers to screening implementation.

According to the WHO indications [15], the project was inspired to the stewardship principles. Stewardship refers to the wide range of functions carried out by governments as they seek to achieve national health policy objectives [16]. It aims at: generating intelligence; formulating strategic policy direction; ensuring tools for implementation such as powers, incentives, and sanctions; building coalitions and partnerships; ensuring a fit between policy objectives and organizational structure and culture; ensuring accountability.
One of the aim of the stewardship action was to provide the regions and the local screening programs with tools that could help planning of improvement actions. The logical framework adopted for these tools was the PRECEDE-PROCEED model [17] an operational approach developed to define and implement complex health promotion interventions.

The PRECEDE-PROCEED model is widely used to support the process of planning and evaluating actions in the field of health promotion with a multidimensional and multi-disciplinary structure. The PREC EDE-PROCEED model assumes that health and health behaviors are influenced by multiple factors - epidemiological, socio-psychological, administrative, political, environmental - which must be considered and assessed for their modifiability in order to ensure effective interventions.

\section{PRECEDE PROCEED AUDIT: the national experience}

The aims of the project were to:

1 analyse barriers and factors which facilitate the implementation and participation in cancer screening programs in three Italian macro-areas (North, Center, South);

2 provide support for screening planning in order to overcome regional and local differences in the implementation of the programs;

3 develop a tool for planning screening programs based on the PRECEDE-PROCEED model, favouring the implementation of interventions based on the best available evidence and tailored to the specific local context.

In the first part of the project, AGENAS used some available data sources (National Health Interview [18] behavioral risk factor national survey [19], and official statistics from the Centre for Screening Monitoring [2]) to conduct an analysis of screening test uptake and screening program implementation in Italy. The analysis showed strong differences between northern and southern Italy, but it also identified modifiable barriers and facilitating factors, such as the presence of opportunistic screening.

During the project, AGENAS contacted all the regional health authorities for a survey on regional screening organization, management of screening, and stewardship toward the local health authorities for cancer screening programs. The results highlighted the regional governments' poor support of local screening programs.

The project had two outputs: 1) an executive summary containing a description of barriers and facilitating factors; 2) a tool, based on the PRECEED-PROCEDE 
model, which helps planning actions to improve screening programs [20].

The tool developed at the end of the AGENAS project was a planning application that was tested in 7 Italian Local Health Authorities (LHAs), including 3 LHAs in region of Lombardy [20]. The test included a preparatory phase in which the LHAs were asked to collect data and documents, a site visit, and then a phase providing the possibility of using the application for planning actions to improve the screening program.

\section{PRECEDE-PROCEED AUDIT: the region of Lombardy experience}

The General directorate of Welfare of Region of Lombardy (DGW-LR), starting from the AGENAS pilot project, decided to launch a program to improve breast cancer screening implementation and participation by designing a peer-to-peer audit system and a software application to help planning interventions to improve screening programs at local level.

The aim of this study is to describe the experience of the region of Lombardy Health System in defining and testing usability a software application and an audit cycle based on the PRECEDE-PROCEED model.

\section{Implementation \\ Setting}

According to the Italian guidelines [1], the organization of breast cancer screening programs is mandatory for all regional health systems in Italy. The Italian guidelines are based on the "Quality Assurance European Guidelines" [21] according to which: the target population is all women aged 50-69 and the screening test is a mammography in two projections, with double reading, performed every 2 years.

The Region of Lombardy is located in Northern Italy, the wealthiest part of the country, and is the most populated region in Italy (roughly 10 million inhabitants). Its regional health system, even if inspired by the same equity and universalistic principles, is quite different from those of other Italian regions and it is characterized by a strict separation of the provider function, performed by public or private hospitals, from the third payer and control function, administered by the Local Health Authorities (LHA). The DGW-LR has the duty to guarantee oncologic screening programs targeting the whole population of region of Lombardy. The DGW-LR coordinates and supports the 8 LHAs which include 15 screening centers. The LHAs organize the screening programs, but the diagnostic testing and treatment (mammograms, biopsies and surgical procedures) are performed in accredited private and public hospitals. The two entities are therefore administratively independent (Table 1).

\section{DEVELOPMENT AND TEST of the audit program and software application}

The DGW-LR identified a coordinator of the audit program and a working group that included screening program coordinators and some external experts who had previously collaborated on the AGENAS project [14]. The working group developed a new audit model and a new application.

To develop a model specific to the cancer screening setting, the following three sources were reviewed: the audit model used in Region of Lombardy to assess food safety (every year the DGW-LR audits the LHAs) [22]; a short list of references identified through a scoping review of the scientific literature [13, 23-28]; the results of the AGENAS pilot project.

A new planning application based on the PRECEDEPROCEED model was developed starting from the AGENAS pilot project. All phases of the PRECEDPROCEED model were reanalyzed and readapted by DGW-LR to the screening setting of the Region of Lombardy. Furthermore, a Microsoft Access macro was programmed to render the PRECEDE-PROCEED model more user-friendly and to automate the compilation of reports.

The audit model and the new application were revised with the help of all the coordinators of the 15 screening centers in the region of Lombardy over the course of three daylong training sessions led by an expert in the PRECEDE-PROCEED model, the regional screening program coordinator, and the AGENAS project scientific coordinator.

Day 1 - the LHAs met the PRECEDE-PROCEED model expert, who gave them a theoretical background and subsequently invited them to attempt a local context analysis using the SWOT (Strengths, Weaknesses, Opportunities, and Threats) method to outline the pros and cons of the audit model.

Day 2 - the regional coordinator presented the new planning application based on the PRECEDE-PROCEED model. The participants practiced using the new application for the entire day and gave suggestions on how to improve it (participants were given 1 month after the end of the course to send further suggestions).

Day 3 - a meeting was held to receive suggestions from LHAs. At the end of the training course and after the completion of an assessment test, the participants were credited as 'auditors.'

In 2017, the DGW-LR officially asked the LHAs to use the application and implemented the first audit cycle. Here are reported the quantitative results of the first year of this audit. The results section reports also a comparison between the planning reports produced by the LHA in 2017 using the PRECEDE-PROCEED application and those produced by the LHA in 2016 when 
Table 1 The public health and screening organization in Region of Lombardy

\begin{tabular}{ll}
\hline & Functions \\
\hline $\begin{array}{l}\text { National Healthcare } \\
\text { System }\end{array}$ & The parliament sets the Essential Levels of Care (LEA) and the National Health \\
& Fund. The IMH, with the support of the National Screening Monitoring Centre, \\
& agrees with regional governments the operational definition of the screening \\
& LEA, the monitoring of LEA-related indicators, objectives for implementation \\
& and quality assurance, and budget criteria for fund allocation (linked to objec- \\
& tives). The National Plan of Prevention, the national guidelines for screening \\
& and the screening reporting system are the main tools for this task.
\end{tabular}

Healthcare System of General directorate of Welfare of Region the Region of Lombardy of Lombardy (DGW-LR) Prevention Unit

8 Local Health Authorities (LHA) - including 15screening centers

public accredited hospitals (27) and private accredited hospitals -defines budgets, rules, objectives for Local Health Authorities, which are the payers, and for hospital and clinic trusts (called Territorial Health Social Trusts), which are the providers;

- coordinates and supports Local Health Authorities;

- manages regional "monitoring system" (database) to guarantee oncologic screening to all citizens of the Region of Lombardy evaluating data reported by the LHAs;

-reports performance indicators to $\mathrm{IMH}$.

- make agreements with the Territorial Health Social Trusts and with the hospitals with regard to the number of medical exams of screenings (mammograms, fecal immunologic tests, colonoscopies, pap tests, etc) - control the quality of medical exams -report data to DGW-LR

- manage the "call-recall system" (send letters, recall, manage website, etc.) -manage communications with patients (by e-mails, call center)

-elaborate performance and early outcome population-based indicators - evaluate the performance of each hospital and refer the data of activities to DGW-LR.

- do medical exams of screening, assessment and treatment - report data to LHAs producing a planning report was mandatory but no audit framework was adopted. The comparison is based on a content analysis; DGW-LR analyzed clarity and completeness of each plan: analysis of the weakness of the program, description of the improvement actions, monitoring plan, definition of quantifiable indicators for monitoring implementation and impact. The results were used to develop the audit model described in this paper.

\section{Results: adapting and testing the model}

The project produced two main outputs: an audit system for cancer screening and a new planning application based on the PRECEDE-PROCEED model.

\section{The audit system for breast cancer screening}

The audit cycle starts by setting a date for the site visit via an email to the LHA at least 1 month prior. The audit is led by two external auditors: a regional coordinator and a representative from another LHA.

The visited LHA team has the opportunity to discuss issues, solutions, and outcomes with the two auditors during the visit.

At the end of the site visit, the external auditor writes a report and delivers it within 1 week to the visited LHA. Within 3 weeks from the visit the LHA defines and sends to the DGW-LR an improvement plan. Then the regional coordinator analyzes and evaluates any possible comment and additional actions within 4 weeks from the audit. The regional coordinator monitors the
LHA plan at 3-6-9-12 months after the audit. The DGW-LR does not use LHA interim indicators at 3-6-9 months to evaluate LHA performances, only evaluating the results yearly.

\section{The planning application based on precede- proceed}

Starting from the prototypal tool produced by the national project, a software for the user-friendly adoption of the planning application was produced. The application was able to support the audit cycle (the software is attached, a free viewer to use Microsoft Access 2010 is available at https://www.microsoft.com/it-it/download/ details.aspx?id=10910).

The original Green \& Kreuter The PRECEDEPROCEED model consists of 9 phases [17]. We applied the phases of the PRECEDE PROCEED model to the setting of organized cancer screening, with some adaptations (Table 2).

\section{Phase 1: social diagnosis}

The objective of the Social Diagnosis is to analyze the setting where the screening will take place, identifying and evaluating the social problems that may influence the achievement of our goal. Since regional authorities have the duty to meet people's needs through political strategies, we assumed that the background Social Diagnosis had already been performed according to the Italian National Prevention Plan [29]. 
Table 2 Description of the PRECEDE-PROCEED model according to Green and Kreuter [17] and its tailoring for screening program setting as developed in the region of Lombardy audit model

\begin{tabular}{lll}
\hline & original Green \& Kreuter & tailored for screening setting \\
\hline $\begin{array}{l}\text { Phase 1 - Social } \\
\text { Diagnosis }\end{array}$ & $\begin{array}{l}\text { Identifies and evaluates the social problems which impact the } \\
\text { quality of life of a specific population }\end{array}$ & $\begin{array}{l}\text { The General directorate of Welfare of Region of Lombardy } \\
\text { identifies outcomes and negotiates targets with Local Health } \\
\text { authority (LHA) according to regional targets and local } \\
\text { setting }\end{array}$ \\
$\begin{array}{l}\text { Phase 2 - } \\
\text { Epidemiological }\end{array}$ & $\begin{array}{l}\text { Establishes program objective considering the target } \\
\text { population }\end{array}$ & $\begin{array}{l}\text { Screening program is described by indicators and } \\
\text { epidemiological critical issues are identified }\end{array}$
\end{tabular}

Diagnosis

Phase 3 - Behavioral Establishes which factors are linked to health problems and, if \& Environmental modified, can sustain the change process (predisposing,

Diagnosis enabling and reinforcing factors).

Phase 4 - Education Identifies the presence of the factors categorized in Phase 3 \& Organizational

Diagnosis

Phase 5 -

Administrative \&

Policy Diagnosis

Phase 6 Implementation

Phase 7 - Process Evaluation

Phase 8 - Impact Evaluation

Phase 9 - Outcome Evaluation
Focuses on the administrative and organizational concerns, which must be considered prior to program implementation. Program objective has to be assessed as compatible with the administration and policy

Converts program objectives into actions through policy changes, regulation and organization

Evaluates the process of implementation

Measures the program effectiveness in terms of intermediate objectives and changes in predisposing, enabling, and reinforcing factors

Measures change in terms of overall objectives and changes in health, social benefits or the quality of life.
The LHA can read evidenced-based reviews on which factors are linked to health problems in screening setting and, if modifiable, can sustain the change process

The LHA identifies the presence of evidence-based actions or best practices; analyzes the relationships with key partners; identifies other critical conditions. In this phase organizational critical issues are identified

LHA is asked to define priorities (high, medium, low, and very low) and possible solutions for every critical issue. If no solution is feasible, the resources needed must be quantified and sustainability must be verified.

Converts program objectives into actions: output and outcome indicators are requested

Evaluates the process of implementation at 3-6-9-12 months from the beginning of the intervention.

Measures changes in the main indicators of screening uptake: participation and test coverage

Measures change in terms of efficacy of screening (sensitivity): interval cancer and advanced cancer incidence
Furthermore, we considered that the international literature had already defined indicators for the screening setting [30]. Therefore, the Ministry of Health [29] and the DGW-LR identified outcomes considered necessary to evaluate a screening program (i.e., "participation rate"). The DGW-LR and the LHA then negotiated thresholds (Table 3) for all identified outcomes (i.e., participation rate $>60 \%$ ) to be achieved according to regional objectives and the local setting. The software is flexible and the pre-defined objectives can be changed by adding or removing items from the grid.

\section{Phase 2: epidemiological diagnosis}

The epidemiological diagnosis includes a picture of performance and early outcome indicators of local screening programs and of the burden of disease of breast cancer. The data for this phase are provided by the coordinating center at the regional level and can support a better framing of the intervention objectives and priorities. This phase includes all outcomes considered in Phase 1 and other outcomes useful to describing the burden of disease and the exposure to risk and protective factors in the population (for example breast cancer incidence, spontaneous screening uptake). Starting from the differences between targets to reach (Phase 1) and actual data (Phase 2), the software automatically fills in an EPIDEMIOLOGICAL CRITICAL ISSUES REPORT and a MISSING DATA REPORT. The list of epidemiological items can also be modified.

\section{Phase 3: behavioral \& environmental diagnosis}

During the Behavioral \& Environmental Diagnosis phase the LHAs are not required to take an active role but they have to review the scientific literature on the uptake processes and the quality of the service provided. The application presents a list of factors that have an impact on the target population concerning cancer screening. Phase 3 is based on the systematic reviews conducted for the Italian HTA report on methods to increase participation in screening programs [13]. The list of factors will be periodically updated as soon as new relevant systematic reviews conducted with appropriate methodology are published; the next update has been planned after the release of the European Recommendations on this topic by the European Commission Initiative on Breast Cancer [31].

\section{Phase 4: education \& organizational diagnosis}

The Education \& Organizational Diagnosis phase aims to assess the presence of two elements (for each LHA and for each of its hospitals and districts): 
Table 3 Indicators used for the social (A) and epidemiological diagnosis (B). In many cases there are international, national or locally defined standards. For the indicators included in the social diagnosis specific objectives should be agreed between the General directorate of Welfare of Region of Lombardy (DGW-LR) and the local health authorities (LHA)

\begin{tabular}{|c|c|c|c|c|}
\hline Indicators & $\begin{array}{l}\text { Italian mandatory } \\
\text { standards (LEA) }\end{array}$ & $\begin{array}{l}\text { recommended } \\
\text { standards }^{\text {a }}\end{array}$ & $\begin{array}{l}\text { standards set by the } \\
\text { DGW-LR }\end{array}$ & Note \\
\hline$\%$ coverage screening & $>55 \%$ & & & $A^{c}$ \\
\hline $\begin{array}{l}\% \text { advanced cancer screen detected (stage }>=2 \text { ) at } \\
\text { subsequent exams }\end{array}$ & $<25 \%$ & & & $A^{c}$ \\
\hline \%screen detected cancers without staging & $<10 \%$ & & & $A^{c}$ \\
\hline \% Participation rate & & $75 \%$ & & $A^{c}$ \\
\hline$\%$ letters not delivered & & & $<5 \%$ & A \\
\hline$\%$ patients excluded post invitation & & & $<10 \%$ & A \\
\hline$\%$ patients with "waiting for recall $<=28$ days" & & $>90 \%$ & & $A^{c}$ \\
\hline $\begin{array}{l}\text { \% people excluded before invitation on total population } \\
\text { target }^{\mathrm{b}}\end{array}$ & & & $>0 \%$ & $A^{c}$ \\
\hline$\%$ people invited on total population target & & & $>90 \%$ & $A^{c}$ \\
\hline$\%$ rate of interval cancers $0-11$ months & & & $<10 \%$ & B \\
\hline$\%$ rate of interval cancers $12-23$ months & & & $<40 \%$ & B \\
\hline$\%$ recall rate first exams & & $<7 \%$ & & A \\
\hline$\%$ recall rate (subsequent examinations & & $<5 \%$ & & A \\
\hline $\begin{array}{l}\% \text { screen-detected cancers compared to the total of can- } \\
\text { cers detected }\end{array}$ & & & $>30 \%$ & B \\
\hline average call time (in months) & & 24 & 24 & A \\
\hline rate of interval cancers $\times 1000$ & & & $<3$ & A \\
\hline sensitivity (proportional incidence) & & & $>70 \%$ & A \\
\hline sensitivity (screen detected / observed) & & & $>65 \%$ & A \\
\hline$\%$ overall coverage (screening and extra screening) & & & $>80 \%$ & B \\
\hline$\%$ PPV & & & $>7 \%$ & B \\
\hline$\%$ prevalence & & & to define locally & B \\
\hline Incidence & & & to define locally & B \\
\hline rate of interval cancers $\times 1000$ & & & $<1,5$ & B \\
\hline sensitivity (proportional incidence) & & & $>70 \%$ & B \\
\hline sensitivity (screen detected / observed) & & & $>99 \%$ & B \\
\hline$\%$ coverage $45-49$ & & & $>50 \%$ & B \\
\hline
\end{tabular}

$\mathrm{A}=$ indicators for social diagnosis; these indicators are mandatory and are defined by the regulatory system. Data for these indicators are collected centrally by the DGW-LR and standards are fixed

$B=$ indicators only for epidemiological diagnosis, data are collected locally by the screening programs

${ }^{a}$ GISMA Italian scientific society of breast screening or European guidelines on Breast cancer

${ }^{b}$ the majority of screening centres don't calculate this indicator

c mandatory

a) EVIDENCE-BASED (EB) ACTIONS OR BEST PRACTICES: the screening program coordinator of the LHA needs to specify which of the evidencebased actions and best practices have been implemented in the local screening program (for example, invitation with fixed appointment, doubleblind reading mammography, counselling). For each EB action or best practice, the LHA has to declare whether EB actions are implemented, their quality level, and any critical issue. b) RELATIONSHIPS WITH KEY PARTNERS: the screening program coordinator of the LHA needs to specify the quality of relationship with stakeholders: the hospital (radiology department, hospital management, pathological anatomy department, etc.), the district (district headquarters, general practitioners), and the community (patient associations, nonprofit organizations, etc.), the departments of LHA (health department, administrative area, etc.). The LHA must declare 
the quality of its relationship with each stakeholder (highly collaborative, collaborative, not

collaborative) and any critical issue.

The users also have the opportunity to add any other conditions that may influence the screening program outcomes which are not in the software form.

The DGW-RL provides a list of evidence-based interventions from systematic reviews [13, 27] and best practices, as well as of possible partners, to focus the LHAs' attention on some characteristics considered important in managing a screening program, thus performing a stewardship function.

When the LHA certifies that there is no evidencebased intervention (or relationship with key partners) available, or that those available are of low quality, or that there are some issues involved, the software identifies that item as an organizational critical issue. The software automatically composes a list of critical issues. This analysis identifies those conditions that influence any predisposing, enabling, or reinforcing factors. At the end of this phase, the planning application stimulates public health operators to identify which epidemiological indicators are most likely related to one or more organizational issues.

\section{Phase 5: administrative $\&$ policy diagnosis}

During the Administrative \& Policy Diagnosis phase, the LHA is asked to define priorities (high, medium, low, and very low) and possible solutions for each critical issue. If no solution is feasible, the planning application requires a description and a definition of the resources needed and a verification of the sustainability.

At the end of this phase, the software automatically generates three reports: the ORGANIZATIONAL CRIT ICAL ISSUES WITH NO SOLUTION report, the UNSU
STAINABLE SOLUTIONS report, and the LOW PRIORITY ISSUES report (Table 4).

\section{Phase 6: implementation}

During the Implementation phase, the LHA defines the expected outcomes and the process indicators for each solution identified in Phase 5 that was considered medium or high priority and sustainable.

At the end of this phase the software automatically generates two additional reports: the SOLUTIONS TO BE ACTIVATED REPORT and the SOLUTIONS FOR EPIDEMIOLOGICAL CRITICAL ISSUES REPORT (for any epidemiological critical issue found, the identified solutions are described by matching the epidemiological and organizational issues identified in PHASE 4). the LHA can use the reports to draw up a more analytical document with a specific improvement plan.

\section{Phase 7: process evaluation}

In this phase the regional screening program coordinator collects the LHA's reports on the intervention implementation.

The regional screening coordinator can evaluate the indicators at 3-6-9-12 months from the beginning of the intervention.

\section{Phases 8-9: impact \& outcome evaluation}

During the Impact \& Outcome Evaluation phase, the LHA evaluates the performance and the early outcome indicators of the screening program (for example, participation rate, detection rate, interval cancer rate, and sensitivity).

All the reports are for internal use, the SOLUTIONS TO BE ACTIVATED REPORT will be used to set up an implementation plan. Furthermore, some of the contents of the reports, particularly the analysis of the

Table 4 The outputs of the planning application. 7 reports

\begin{tabular}{ll}
\hline REPORT & DESCRIPTION \\
\hline $\begin{array}{l}\text { 1. Epidemiological Critical Issues } \\
\text { report }\end{array}$ & $\begin{array}{l}\text { summarizes the critical issues identified during the epidemiological analyses, mostly indicators that do not reach } \\
\text { the agreed standards (Phase 2). } \\
\text { 2. Missing Data report }\end{array}$ \\
$\begin{array}{ll}\text { 3. Critical Issues with No Solution } \\
\text { report }\end{array}$ & $\begin{array}{l}\text { summarizes the identified problems without a solution; to look for a solution the LHA can carry out a literature } \\
\text { review and ask the scientific society for help. }\end{array}$ \\
$\begin{array}{ll}\text { 4. Low Priorities report } \\
\text { 5. Unsustainable Solutions report }\end{array}$ & $\begin{array}{l}\text { summarizes the problems and related solutions for which the administrative and policy analysis concluded there } \\
\text { were no resources available. The screening operator can renegotiate the budget with the LHA general } \\
\text { management or can search for external funds (agreements with other agencies, universities, nonprofit } \\
\text { organizations, etc.). } \\
\text { the implementation plan reporting all the medium-high priority problems for which a solution has been identi- } \\
\text { fied and resources are available. } \\
\text { correlates the epidemiological critical issues (identified in report 1) to the solutions to be activated (identified in } \\
\text { Critical Issues report }\end{array}$
\end{tabular}


relationships with key partners and stakeholders, are strictly confidential. This kind of information can be shared only during the site visit by the regional coordinator; it cannot be made public in official documents.

\section{Results of the FIRST round of audit adoption}

A systematic analysis and synthesis of the action plans produced in 2016 by the LHAs was difficult because the documents presented were extremely heterogeneous in their structure and in presented contents. Nevertheless the analysis of clarity and completeness of these plans showed that the most common weakness was the monitoring plan: completely absent in most cases and not including quantifiable indicators in the remaining. This lack essentially rendered ineffective any attempt by the regional coordinating center and by the DGW-LR to evaluate the plan implementation.

The first round of audit adoption involved 4 out of the 15 screening centres ( 3 other centres were involved in the pilot phase). The centres were chosen by the DG welfare in relation to the availability of the centres themselves and their performance: 2 centres with excellent performance, 2 centres with poor performance. All centres presented an improvement plan according to the PRECEDE-PROCEED tool framework. Overall, the 4 audits identified 232 critical issues (ex. invitation without fixed appointment; all issues are visible in MS Access attached). After the Administrative \& Policy Diagnosis phase, the issues were classified as: $27 \%$ low priority issues, $15 \%$ not sustainable solutions, $5 \%$ issues without a solution. For some of the issues with no sustainable solution, the auditors proposed a sustainable solution during the first feedback that was not found by the visited LHA team; these were added to the final version of the improvement plans (Table 5). The plan included the predefined monitoring form with milestones to be reached at $3,6,9$, and 12 months, with relative indicators and standards.

\section{Discussions}

\section{Audit}

In this model, planning has a time frame of 1 year in which health professionals can easily understand their roles and define their activity based on annually assigned objectives.

The software and the audit system have been designed as tools for a governance action based on the stewardship principles as defined by the WHO: the "careful and responsible management of the well-being of the population." [32] The stewardship role of the health systems, which aims at ensuring the promotion of people's wellbeing, was adopted by the WHO European region in 2008 with the Tallinn Charter [33] and further elaborated in the Italian context according to the 2010-2013 National Preventive Plan [34]. This role encompasses not only the main stewardship functions at national level but also the function of coordinating the regional and local health authorities.

The first round of audit identified many critical issues: this was expected as it was a systematic analysis of the whole process. It is specified that the criticalities also include potential actions to improve the service. The improvement is agreed with the head of the screening center.

\section{The PRECEDE-PROCEED tool}

The application of the PRECEDE-PROCEED model to screening programs has been validated by several case studies: a systematic review found 8 such studies [35]. All of them were performed in the US and took into account mainly Phase 4 (Education \& Organizational Diagnosis), which investigates predisposing, enabling and reinforcing factors. Technical and organizational factors emerged as the most important changeable variables because they act directly on participation (including vulnerable groups) and because they work on highly modifiable factors.

Table 5 Results of the audits conducted in 2017 in four LHAs using the PRECEDE-PROCEED tool

\begin{tabular}{|c|c|c|c|c|c|c|c|}
\hline & $\begin{array}{l}\text { EPID } \\
\text { EMIOLOGICAL } \\
\text { CRITICAL } \\
\text { ISSUES }\end{array}$ & $\begin{array}{l}\text { ORGANIZATIONAL } \\
\text { CRITICAL ISSUES }\end{array}$ & $\begin{array}{l}\text { LOW } \\
\text { PRIORITY } \\
\text { ISSUES }\end{array}$ & $\begin{array}{l}\text { NOT SUSTAI } \\
\text { NABLE } \\
\text { SOLUTIONS }\end{array}$ & $\begin{array}{l}\text { CRITICAL ISSUES } \\
\text { WITHOUT A } \\
\text { SOLUTION }\end{array}$ & $\begin{array}{l}\text { SOLUTIONS } \\
\text { TO BE } \\
\text { ACTIVATED }\end{array}$ & $\begin{array}{l}\text { \% SOLUTIONS TO BE ACTIVATE } \\
\text { D / ORGANIZATIONAL CRITICAL } \\
\text { ISSUES }\end{array}$ \\
\hline $\begin{array}{l}\text { LHA } \\
\mathrm{A}\end{array}$ & 25 & 90 & 14 & 21 & 1 & 54 & $60 \%$ \\
\hline $\begin{array}{l}\text { LHA } \\
B\end{array}$ & 3 & 62 & 16 & 2 & 3 & 41 & $66 \%$ \\
\hline $\begin{array}{l}\text { LHA } \\
\mathrm{C}\end{array}$ & 4 & 22 & 7 & 2 & 5 & 8 & $36 \%$ \\
\hline $\begin{array}{l}\text { LHA } \\
\text { D }\end{array}$ & 10 & 58 & 25 & 11 & 2 & 20 & $34 \%$ \\
\hline TOT & 42 & 232 & 62 & 36 & 11 & 123 & $53 \%$ \\
\hline
\end{tabular}


Our adaptation of the PRECEDE-PROCEED model to plan and conduct an intervention aimed at improving screening programs introduced two unique characteristics:

1- given that priorities are mostly given by the European Commission Recommendation [36], by the Italian guidelines and laws [1], and by the national monitoring system defined by the Ministry of Health $[29,30]$ and by the scientific societies [37, 38] the Social Diagnosis (phase 1) was reduced to the negotiation of thresholds on the main performance and early outcome screening indicators;

2 actions to increase participation in screening programs are already defined by the findings of a recent systematic review sponsored by the Italian Ministry of Health [27].

Regarding the first point, screening programs follow well-defined international guidelines which set several priorities (i.e., target population, standards for recall rate, and sensitivity) that cannot be questioned, at least in the phase of implementing the programs at the local level. The advantage is that these priorities and the guidelines are based on sound studies and strong evidence. It is worth to note, that this approach has been also supported by the new European guidelines, that at least for the 50-69, targeted by the Lombardy screening programs, made a strong recommendation in favor of screening [21].

With regard to the second point, this choice was made in order to reduce the arbitrary selection of possible interventions proposed. It is very important to continually update the items that are proposed in Phase 4.

The plans produced with the tool resulted clearer, more complete and provided with a monitoring including quantifiable indicators. This improvement of the documents produced did not cost more time or workload for screening centers, because the tool automatically framed each single chapter of these documents. The opportunity to speed up the writing of thee improvement plan was particularly appreciated by the screening coordinators already in the 3 days training/tasting workshop.

\section{Conclusions}

With the audit system we want to introduce a "stewardship instrument" to overcome local problems by:

- sharing evidence-based activities to improve screening participation and quality

- standardizing the main characteristics of screening programs in the whole region
- supporting and coordinating the training process of healthcare professionals involved in screening programs

Starting from the application and the audit model developed during this experience, a new audit activity involving all the LHAs was launched in region of Lombardy in 2017. The application helps the LHA screening coordinators to quickly have a clear picture of the situation of the screening program as it highlights both issues and things to do.

The impact of the implementation of the new audit system on screening performance will be evaluated in the next few years.

\section{Availability and requirements}

Project name: Breast Screening PRECEDE PROCEED project.

Project home page: not applicable.

Operating system(s): MS ACCESS (Office 2016 or sup).

Programming language: Microsoft VBA.

Other requirements: Windows 10 or sup.

License: MS ACCESS (Office 2016 or sup), Windows 10 or sup.

Any restrictions to use by non-academics: it is not intended for use outside cancer screening programs; it is not intended to be used for profit.

\section{Supplementary Information}

The online version contains supplementary material available at https://doi. org/10.1186/s12889-020-09842-8.

Additional file 1. Software for precede proceed breast audiT. The software helps health pofessionals to lead an audit in setting of breast screening.

\section{Abbreviations}

GP: General practitioners; AGENAS: National Agency for Regional Health Services; LHA: Italian Local Health Authority; IMH: Italian Minister of Health; DGW-LR: General directorate of Welfare of Region of Lombardy

\section{Acknowledgements}

Gruppo Precede-Proceed: J.A. Bastiampillai, E. Gabrielli, F. Grimaccia, L. Tessandri, M.S. Schivardi, M. Crisetig, R. Bardelli, G. Gola, E. Anghinoni, A Bozzeda, S. Gotti, L. Cavalieri D'Oro, A. Ilardo, G. Moretti, F. Lobuono, E. Merlo, A. Silvestri, G. Beghi, R. Lucchini, G. Marazza, E. Rossetti, N. Leonardo, E. Tidone, A. Lamberti, P. Ceresa, L. Acerbi, L. Camana, G. Magenes, L. Cecconami, A.M. Cioccarelli, S. Domenighini.

\section{Availability of data and material}

Software derived from public resources and is available with the article (attached).

An Italian version is available here.

https://www.siss.regione.lombardia.it/EdmaSissPortaleSitoWebPublic/ disclaimer.do?pag=documentoDiProgetto.jsp\&par=doc\&id=75092781

\section{Authors' contributions}

AF AG GS PGR developted the national model of screening audit using Precede-Proced methodology. DC PGR PL LC improved the model of screening audit using Precede-Proced, methodology for the Setting of Regione Lombardia. DC developted the software. DC LC attivated the audit in regione 
lombardia. PGR DC wrote the manuscript. All authors read and approved the final manuscript.

\section{Funding}

"Not applicable".

\section{Ethics approval and consent to participate}

"Not applicable".

\section{Consent for publication}

"Not applicable".

\section{Competing interests}

The authors declare that they have no competing interests. None of the authors have any competing interests.

\section{Author details}

${ }^{1}$ DG Welfare, Regione Lombardia, Milano, Italy. ${ }^{2}$ Direzione Generale della Prevenzione, Ministero della Salute, Rome, Italy. ${ }^{3}$ Dipartimento di Psicologia, Università di Roma "La Sapienza", Rome, Italy. ${ }^{4}$ ASL Roma 5, Tivoli, Italy. ${ }^{5}$ Gruppo PRECEDE-PROCEED, Regione Lombardia, Milano, Italy. ${ }^{6}$ Università degli Studi di Torino, Torino, Italy. ${ }^{7}$ Azienda Unità Sanitaria Locale - IRCCS di Reggio Emilia, Reggio Emilia, Italy.

Received: 7 September 2019 Accepted: 4 November 2020 Published online: 25 November 2020

\section{References}

1. Ministero della Salute Direzione Generale della Prevenzione. Raccomandazioni per la pianificazione e l'esecuzione degli screening di popolazione per la prevenzione del cancro della mammella, del cancro della cervice uterina e del cancro del colon retto. 2006. Available from: https://www.osservatorionazionalescreening.it/sites/default/files/allegati/ screening vers completa.pdf.

2. Osservatorio NAzionale Screening. Rapporto dell'Osservatorio nazionale screening 2016 [Internet]. 2017 [cited 2019 Apr 3]. Available from: http:// www.osservatorionazionalescreening.it/content/lo-screening-mammografico.

3. Smith-Bindman R, Chu PW, Miglioretti DL, Sickles EA, Blanks R, BallardBarbash R, Bobo JK, Lee NC, Wallis MG, Patnick J, Kerlikowske K. Comparison of screening mammography in the United States and the United Kingdom. JAMA. 2003;290(16):2129-37.

4. Palència $L$, Espelt $A$, Rodríguez-Sanz $M$, Puigpinós $R$, Pons-Vigués $M$, Pasarín $\mathrm{Ml}$, et al. Socio-economic inequalities in breast and cervical cancer screening practices in Europe: influence of the type of screening program. Int J Epidemiol. 2010;39(3):757-65.

5. Giorgi Rossi P, Chini F, Barca A, Baiocchi D, Federici A, Farchi S, Borgia P. Efficacy of disease management profiles: the mammographic screening program of Lazio. Tumori. 2008;94:297-303.

6. Giorgi Rossi P, Camilloni L, Mantellini P, Barile V, Borgia P, Federici A, Mangia M, Paci E, Vella A, Zappa M. Breast cancer diagnostic methods: screendetected and clinical cases. An Italian survey of women's experiences. Tumori. 2007;93:452-60.

7. Giorgi Rossi P, Federici A, Farchi S, Chini F, Barca A, Guasticchi G, Borgia P. The effect of screening programs on the treatment of benign breast neoplasms: observations from current practice in Italy. J Med Screen. 2006; 13:123-8.

8. Costantini AS, Martini A, Puliti D, Ciatto S, Castiglione G, Grazzini G, et al. Colorectal cancer mortality in two areas of Tuscany with different screening exposures. J Natl Cancer Inst. 2008;100(24):1818-21.

9. European Commission Initiatiive on Breast Cancer. Inviting women to screening: Letters vs. no invitation. Available at, last access 13/06/2020 https://healthcare-quality.jrc.ec.europa.eu/european-breast-cancerguidelines/Invitation-to-screening-and-decision-aid/invite-50-69/letters.

10. Schünemann HJ, Lerda D, Dimitrova N, et al. Methods for development of the European Commission initiative on breast Cancer guidelines: recommendations in the era of guideline transparency. Ann Intern Med. 2019:171(4):273-80. https://doi.org/10.7326/M18-3445.

11. Schünemann HJ, Lerda D, Quinn C, et al. Breast Cancer screening and diagnosis: a synopsis of the European breast guidelines. Ann Intern Med. 2020;172(1):46-56. https://doi.org/10.7326/M19-2125.
12. Jepson R, Clegg A, Forbes C, Lewis R, Sowden A, Kleijnen J. The determinants of screening uptake and interventions for increasing uptake: a systematic review HTA Health Technology Assessment NHS R\&D HTA Programme. Health Technol Assess (Rockv). 2000;4(14):1-133.

13. Camilloni L, Ferroni E, Cendales BJ, Pezzarossi A, Furnari G, Borgia P, et al. Methods to increase participation in organised screening programs: a systematic review. BMC Public Health. 2013;13(1):1 Available from: BMC Public Health.

14. Agenzia Nazionale per i Servizi Sanitari Regionali. Implementazione dei programmi di screening: analisi delle barriere e dei fattori facilitanti, modificabili e non. Executive summary. 2014.

15. Travis $P$, Egger D, Davies $P$, Mechbal A. Towards better stewardship: concepts and critical issues WHO/EIP/DP/02.48 [Internet]. World Health Organization. 2002. Available from: http://www.who.int/healthinfo/paper48. pdf\%0Ahttp://www.who.int/entity/healthinfo/paper48.pdf.

16. WHO. Stewardship [Internet]. Health systems. 2019 [cited 2019 Apr 1] Available from: http://www.who.int/healthsystems/stewardship/en/.

17. Green LW, Kreuter MW. Health program planning: an educational and ecological approach. 4rd ed. New York: McGraw-Hill; 2005.

18. Francovich L, Rossi PG, Gargiulo L, Giordani B, Murianni L, Di NA, et al. Screening cervico-vaginali e mammografici in italia: livelli di copertura e differenze socio-economiche (anni 2012-13 ). In: Salute in Italia e livelli di tutela: approfondimenti dalle indagini ISTAT sulla salute; 2016. p. 121-9.

19. Giorgi Rossi P, Carozzi G, Federici A, Mancuso P, Sampaolo L, Zappa M. Invitation coverage and participation in Italian cervical, breast and colorectal cancer screening programmes. J Med Screen. 2018;25(1):17-23.

20. Sinopoli A, Saulle R, Guarino A, Cereda D, Giorgi Rossi P, Serantoni G, et al. Experimenting an instrument for cancer screening programming in Italy. Ig Sanita Pubbl. 2017;73(4):303-9.

21. Perry N, Broeders M, De Wolf C, Törnberg S, Von Karsa L. European guidelines for quality assurance in breast cancer screening and diagnosis; 2006. p. 432.

22. Regione Lombardia. Decreto del Dirigente n. 11493 del 17/12/2015 "Audit dell'autorità competente regionale ai sensi del Reg. (CE) n. 882/2004 - art. 4(6) sulle autorità competenti locali. 2015.

23. Ivers N, Jamtvedt G, Flottorp S, Jm Y, Sd F, Ma OB, et al. Audit and feedback: effects on professional practice and healthcare outcomes ( Review ) SUMMARY OF FINDINGS FOR THE MAIN COMPARISON. 2012:(6).

24. Ivers NM, Grimshaw JM, Jamtvedt G, Flottorp S, O'Brien MA, French SD, et al. Growing literature, stagnant science? Systematic review, metaregression and cumulative analysis of audit and feedback interventions in health care. J Gen Intern Med. 2014;29(11):1534-41.

25. Bonfill Cosp X, Marzo Castillejo M, Pladevall Vila M, Marti J, Emparanza J. Strategies for increasing the participation of women in community breast cancer screening. Cochrane Database Syst Rev. 2003;1.

26. Young C, Skorga P. Stage-based interventions for smoking cessation: a review synopsis. Public Health Nurs. 2010;28(5):441-3 Available from: http:// www.ncbi.nlm.nih.gov/pubmed/22092428

27. Ferroni E, Camilloni L, Jimenez B, Furnari G, Borgia P, Guasticchi G, et al How to increase uptake in oncologic screening: a systematic review of studies comparing population-based screening programs and spontaneous access. Prev Med (Baltim). 2012;55(6):587-96. Available from:. https://doi.org/ 10.1016/j.ypmed.2012.10.007

28. Bankhead C, Richards S, Peters T, Sharp D, Hobbs F, Brown J, et al. Improving attendance for breast screening among recent non-attenders: a randomised controlled trial of two interventions in primary care. J Med Screen. 2001;(8):99-105.

29. CONFERENZA STATO-REGIONI. Seduta del 21.12.2017: Intesa, ai sensi dell'articolo 8, comma 6, della legge 5 giugno 2003, n. 131, tra il Governo, le Regioni e le Province autonome di Trento e Bolzano concernente la proroga del Piano nazionale per la prevenzione per. 2017.

30. Giordano L, Giorgi D, Frigerio A, Bravetti P, Paci E, Petrella M, et al. Indicatori e standard per la valutazione di processo dei programmi di screening del cancro della mammella. Epidemiol Prev. 2006;2(supplemento 1).

31. European Commission. Recommendations from European Breast Guidelines [Internet]. European Commission initiative on breast cancer. 2019 [cited 2019 Apr 1]. Available from: https://ecibc.jrc.ec.europa.eu/.

32. Saltman RB, Ferroussier-Davis $\mathrm{O}$. The concept of stewardship in health policy. WHO Bulletin. 2000;78(6):733-9.

33. Danzon M, Maripuu M. The Tallinn Charter: Health Systems for Health and Wealth [Internet]. WHO European Ministeral Conference on Health Systems: 
"Health Systems, Health and Wealth."; 2008. p. 5. Available from: http://www. euro.who.int/_data/assets/pdf_file/0008/88613/E91438.pdf.

34. Federici A, Filippetti G, Oleari F. National preventive plan: putting stewardship into practice. Ital J Public Health. 2012;9(2):99-105.

35. Federici A, Guarino A, Serantoni G. Participation in oncologic screening programmes: a modelling proposal of the systematic review results according to PRECED PROCEED model. Epidemiol Prev. 2012;36(1):1-104 Green LW, Kreuter, MW. Health Program.

36. Council Recommendation 2 December 2003 on cancer screening. 2003/ 878/EC. [Internet]. European Union. Available from: https://ec.europa.eu/jrc/ sites/jrcsh/files/2_December_2003-cancer-screening.pdf. Accessed 1 Dec 2019.

37. Ponti A, Mano MP, Tomatis M, Baiocchi D, Barca A, Berti R, et al. II "progetto SQTM" sulla qualità di diagnosi e terapia entro i programmi di screening in Italia: risultati 2010. Epidemiol Prev. 2012;36(6 Suppl 1):87-95 Available from: http://www.scopus.com/inward/record.url?eid=2-s2.0-8489250784 0\&partnerlD=tZOtx3y1.

38. Ciatto S, Naldoni C, Ponti A, Giordano L, Giorgi D, Frigerio A, et al. Interval cancers as indicators of performance in screening programmes. Epidemiol Prev. 2008;32(2):93-8.

\section{Publisher's Note}

Springer Nature remains neutral with regard to jurisdictional claims in published maps and institutional affiliations.

- fast, convenient online submission

- thorough peer review by experienced researchers in your field

- rapid publication on acceptance

- support for research data, including large and complex data types

- gold Open Access which fosters wider collaboration and increased citations

- maximum visibility for your research: over $100 \mathrm{M}$ website views per year

At $\mathrm{BMC}$, research is always in progress. 